\title{
Research Needs and Recommendations on Environmental Implications of Additive Manufacturing
}

\author{
David Rejeski ${ }^{1, *}, \mathrm{Fu} \mathrm{Zhao}^{2}$, Yong Huang ${ }^{3, * *}$ \\ ${ }^{1}$ Science and Technology Innovation Program, Woodrow Wilson International Center for \\ Scholars, Washington, DC 20004 \\ ${ }^{2}$ School of Mechanical Engineering and Division of Environmental and Ecological Engineering, \\ Purdue University, West Lafayette, IN 47907 \\ ${ }^{3}$ Department of Mechanical and Aerospace Engineering, University of Florida, Gainesville, FL \\ 32611 \\ * Currently Director, Technology, Innovation, and Environment Project, Environmental Law \\ Institute, Washington, DC 20036 \\ ** Corresponding author, P. O. Box 116250, University of Florida, Gainesville, FL 32611, USA, \\ Phone: 001-352-392-5520, Fax: 001-352-392-7303, Email: yongh@ufl.edu
}

\begin{abstract}
:
Additive manufacturing (AM), commonly known as "three-dimensional (3D) printing," is the process of joining materials to make objects from 3D model data, usually layer by layer. AM provides a cost-effective and time-efficient way to fabricate products with complicated geometries and advanced material properties and functionality. Based on the 2014 National Science Foundation (NSF) Workshop on Environmental Implications of Additive Manufacturing, this paper outlines potential environmental implications of AM related to key issues including
\end{abstract}


energy use, occupational health, waste, lifecycle impact, and cross-cutting and policy issues, in terms of their current state-of-the-art, research needs, and recommendations, respectively.

Keywords: Additive manufacturing, Environmental Implication, Research need, Recommendation

\section{Introduction}

Additive manufacturing (AM) technologies enable the joining of materials to make objects from three-dimensional (3D) model data, usually layer by layer. Commonly known as "3D printing," AM offers many advantages over other manufacturing processes: parts can be made easily ondemand for customization and personalization, no special tooling is required for part fabrication, material waste is greatly reduced, the time and cost of manufacturing can be reduced significantly for individualized parts and small-quantity productions, novel components and structures with complex geometries and heterogeneous compositions can be fabricated without difficulty using some AM technologies, and the supply chain is compressed drastically [1]. Since its inception in the mid-1980s, AM has evolved and blossomed into a plethora of processes, and is now enabling "on-demand" manufacturing and drastically reducing inventories and wait times. According to the 2013 Wohlers Report [2], the compound annual growth rate of worldwide revenues of all AM products and services over the past twenty five years was $25.4 \%$.

It has been long recognized that AM may offer various environmental benefits, such as less material waste, energy efficiency, and transportation impact reduction by manufacturing locally or on site, compared with conventional manufacturing. As a potentially transformational 
technology, AM could be used to advance sustainability, but as with other disruptive technologies - from nanotechnology to synthetic biology - there is no guarantee that this will happen. Similar to traditional manufacturing processes, AM consumes materials and energy and generates emissions thus carries its own environmental footprint. It is even noted that AM may herald the apotheosis of consumerism, instant gratification, and the throwaway society instead [3], all of which may impose negative impacts on the environment. Such research topics have drawn interest from researchers in areas such as industrial ecology and environmental engineering. However, assessing AM environmental implications is neither simple nor inexpensive due to the increasing variety of options affecting AM, including material (polymers, metals, ceramics, composites, and biological materials), feedstock form (liquid, powder, filament, and sheet), process (from material extrusion to powder bed fusion to directed energy deposition), location (industrial facility, maker space, and home), and post-processing options. In fact, it has been pointed out that both opportunities and challenges exist for AM to contribute to environmental sustainability [4-6].

In order to better examine the environmental implications of AM, the National Science Foundation (NSF) sponsored an NSF Environmental Implications of Additive Manufacturing workshop on October 14-15, 2014 at the NSF Headquarters in Arlington, Virginia. The workshop objective was to provide a forum for disseminating information and sharing ideas about the emerging technology of AM and its impact on the environment and occupational health. The workshop reviewed the existing research on the environmental impacts of additive manufacturing (including energy and embodied energy), identified knowledge gaps and uncertainties that could help inform an agenda for future research into the environmental impacts 
of AM, and expanded the research community focused on environmental and energy-use issues in AM. The workshop had 96 officially registered participants including researchers with backgrounds in industrial ecology, energy and materials mass balance assessments, lifecycle analysis, and environmental risk assessment.

As part of the outcomes from the 2014 NSF workshop on Environmental Implications of Additive Manufacturing, this paper summarizes the current state-of-the-art, research needs, and recommendations from the workshop participants [7] and further incorporates most recent advances in the field. As shown in Figure 1, five key issues have been identified and discussed regarding environmental implications of AM: energy use, occupational health, waste, lifecycle impact, and cross-cutting and policy issues; in particular, cross-cutting and policy issues overlap with other topics.

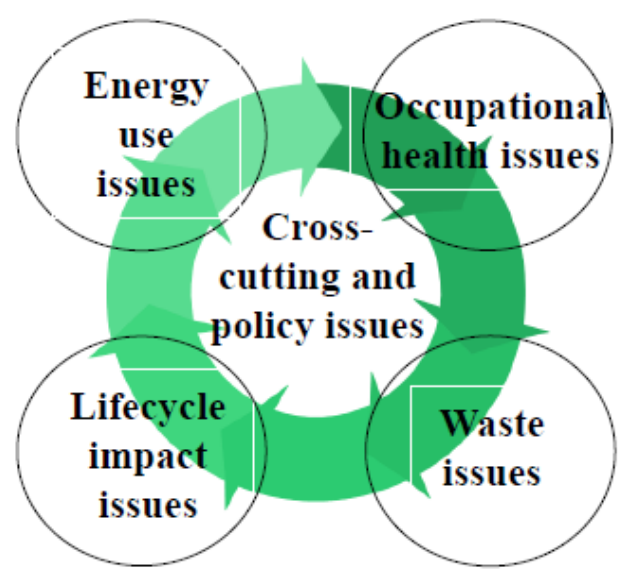

Figure 1. Five key issues related to environmental implications of AM 


\section{Current State of the Art}

\subsection{Energy Use Issue}

Because of the unique nature of AM technologies, various key questions surround its energy impacts. In the past decade, many efforts have been made to understand the energy consumption of AM processes. In fact, energy use has attracted much more attention than other environmental dimensions of AM technologies. It is expected since energy consumption is directly related to manufacturing cost and carbon emission. For most AM processes, 3D printers use more energy than that of comparable conventional processes at process or machine levels. Industrial AM fusion methods using metal powders and high-energy beams can consume much more electricity per unit output than conventional manufacturing methods. In addition, AM feedstock may carry higher embedded energy. However, AM allows complex parts to be produced in a single step with minimal wastes, and avoids the energy impacts of multiple part production and subsequent assembly. Furthermore, complex geometry unachievable using traditional manufacturing technologies becomes possible, which leads to lightweight and improved performance during use phases. In some cases, AM methods have been shown to be more efficient for low production runs as no tooling or fixture is needed, but conventional methods become more efficient for higher production quantities. The improved material efficiency and potential savings during use phases necessitate holistic analysis of energy consumption, which has been included in many LCA studies [8-10], which will be discussed in details later in this paper.

Generally, for many AM processes, the energy consumption of building a single part using different printing parameters has been well studied, including many studies on laser sintering process [11-15] and fused deposition modeling (FDM) [11, 16, 17], as well as few studies on 
binder jetting [18-20], Stereolithography [21], electron beam melting (EBM) [22, 23], and thermojet [11]. For EBM process, it has been pointed out that energy consumption is almost independent on shape complexity [23]. For building multiple parts, it has been observed that specific energy consumption in terms of energy per mass $(\mathrm{MJ} / \mathrm{kg})$ of materials deposited or energy efficiency is highly dependent on capacity utilization, especially for metal powder-based technologies [24].

One major challenge to understanding the energy efficiency of AM is the fact that machines vary widely in how much energy they use and the energy use is dependent on a variety of variables, ranging from materials to load and use patterns. Fortunately, various models [18, 21] have been developed to break down the total energy consumption to components or subsystem levels as a promising approach to address this challenge. However, given the large number of AM machines with different configurations how to develop material/energy flow models with minimal experimental efforts remains to be addressed.

\subsection{Occupational Health Issue}

AM processes have the potential to reduce hazards that are endemic to many conventional manufacturing processes - they may in principle be self-contained, use less materials, and produce less waste. Yet they also present the possibility of emergent safety risks. Understanding and addressing both potential occupational health risks and benefits of AM to users across the board is critical to the fully realizing advantages brought by AM technologies. 
While many forms of AM present a step change from conventional manufacturing techniques, the health and safety risks they present are often not that dissimilar to those found in any industrial setting. For example, working with hazardous materials, operating processes that can cause physical injury, and managing harmful emissions during AM are common to many forms of manufacturing. However, AM technologies also give rise to emerging risks. For example, while emissions from AM processes may be similar to their counterparts in traditional manufacturing due to similar process conditions and mechanisms, the use of unconventional materials during AM may bring up different occupational health concerns. Many recent studies have confirmed the emission of particulates (including ultrafine particles as small as 1-3 nm) and volatile organic compounds (VOCs) from FDM [25-27] and binder jetting processes [20] in office and lab settings. It is suggested that the particles are formed due to nucleation of semivolatile vapors emitted from heated feedstocks [28]. Iron-containing and soot-like particles are observed but it remains unclear whether these are due to contamination [29]. Using high temporal resolution scanning, Simon et al. [30] have reported that particulate matter emission is closely correlated with printing heat movement and features being printed. Most of these studies use acrylonitrile butadiene styrene (ABS) and polylactic acid (PLA) filaments and in general ABS leads to higher VOC emission (more than half as styrene). To reduce exposure, enclosing printers and installing high-efficiency particulate air (HEPA) filters at exhaust have been suggested [31], among other strategies [32]. One pilot study has also confirmed the operator's exposure to metal particles during powder handling and laser sintering [33]. 


\subsection{Waste Issue}

Unique characteristics of AM processes [1] mean there is potentially less waste produced when compared with conventional manufacturing processes. However, process wastes still exist and in some cases the amount can be much higher than expected due to human and machine errors [34]. For powder bed based AM processes such as laser sintering and EBM, powders can be recycled but only to a limited times due to the compositional change and property deterioration [35-38]. It has been suggested that the waste polyamide powders from laser sintering may be used to make filaments for FDM processes [39]. There are also efforts on reducing the environmental impacts of support structures needed during printing [40]. However, the distributed nature of AM raises questions about the amount of waste that could be generated in non-industrial settings and the economic feasibility of waste collection and recycling.

In addition to process wastes, management of failed prints and end-of-life products made via AM technologies brings some interesting issues especially for polymer parts. Distributed or localized recycling of waste filaments and waste parts have been proposed using customer developed extruders such as RecycleBot [9]. Attempts have also been made to remanufacture filaments from 3D printed PLA reinforced carbon fiber composite parts [41]. In general, mechanical properties may deteriorate during remanufacturing thus virgin polymers [42] or performance enhancing additives [43] are needed. With the rapid development of 3D printer markets especially the FDM market, the number of material types used for filament manufacturing will also increase. Filaments of different brands may be based on proprietary formulas with undisclosed additives for better printing performance. This increased material complexity along with localized filament remanufacturing efforts could certainly introduce additional challenges to 
plastic recycling. To minimize environmental impacts due to these wastes, efforts have been made to develop biodegradable or bio-based compostable filaments but the most common biobased PLA filament still has issues such as low mechanical strength, poor moisture resistance, and part swelling [42].

\subsection{Lifecycle Assessment Issue}

LCA has emerged as the widely accepted method to evaluate the impacts on resource depletion, human health, and ecosystem of a product, process, or system. LCA takes a holistic view and covers all activities involved from raw material acquisition to disposal at the end of life. Among other things, LCA helps understand the cumulative environmental footprint of subjects of interest and informs decisions about materials, designs, processes and supply chains while considering trade-offs among life cycle stages and impact categories. In the past decade, LCA has found many applications in supporting the advancement of sustainable manufacturing [44].

The potential of AM to produce complex objects at little or no additional cost raises interesting questions for LCA, particularly whether energy consumption increases with additional complexity and what implications that might have for part performance during its use phase. Clearly all the data and knowledge gained through efforts discussed in the previous energy use, occupational health, and waste sections are needed for an LCA on AM processes or products made via AM but a "complete" LCA requires more data and information. Early work on LCA of AM has largely been focusing on energy consumption [8] but recent studies have expanded to include material consumption, cover more environmental impact categories, and explore different machine operations [45-48]. In particular, Kellens et al. [49] have summarized the 
process level life cycle inventory (i.e. direct process energy and material consumption) for a series of AM processes including selective laser melting, selective laser sintering, EBM, FDM, and stereolithography. For binder jetting, energy and material flows have also been analyzed [19]. The large variation among reported data of differences for the same AM technology likely originates from different machine tool designs, applied process parameters (e.g. layer thickness), machine tool utilization (single part versus full build), and selected case study materials and part designs [49]. Even more, a recent LCA study on mug printing and mass production has revealed the significant impacts from the experience level of 3D printer users [50]. Such observations may explain the conflicting LCA conclusions drawn by different researchers when comparing AM technologies with traditional manufacturing processes $[9,51,52]$. It should also be noted that very limited data is available on manufacturing of AM feedstocks; some rough estimates are commonly used, which adds significant uncertainties to LCA results.

\subsection{Cross-cutting and Policy Issue}

In addition to the topic areas discussed above, there exist some issues that are cross cutting and at higher levels. It has been pointed out [42] that remanufacturing of filaments may introduce contaminants which in turn could affect the emission of particulate matters and VOCs. With the development of small extruders such as RecycleBot [9], it may become possible to convert used plastic products into feedstocks for 3D printing on site [53], which brings potential environmental benefits. Analysis has also been done to estimate the potential saving on primary energy and greenhouse gas emissions by 2025 due to implementation of AM [54]. A framework aiming at integrating LCA and occupation health risks has been proposed [55]. Moreover, LCA as an analysis tool cannot be used to support product designs and process improvement directly. 
Some framework has been proposed to integrate LCA with computer-aided design so environmental performance can be estimated during product designs $[56,57]$. Technology wise, AM holds significant potential contributing to sustainability, it has been recognized that AM, in combination with other emerging technologies/systems such as the Internet of Things and Industry 4.0, has been shifting the manufacturing paradigm thus the full consequence is hard to foresee [5].

It should be noted that AM technology raises a variety of potential policy issues that go well beyond technology development. The distributed nature of AM could pose potential emergent risks. While industrial users of the technology would operate within existing regulatory and governance frameworks, an increase in novel workplaces for AM, such as job shops and makerspaces or even garage/basement, could raise new issues regarding policy guidance and standard compliance [58]. 3D bioprinting [59], which employs AM techniques to pattern and print cellular materials and may support significant medical advances, may raise its own regulatory and disposal questions. Other questions raised by $\mathrm{AM}$ in areas such as public perception, liability and legal issues, trade agreements, material traceability agreements and security issues will need to be addressed as the technology advances.

\section{Key Issues and Their Research Needs}

The following sections summarize the five key issues and present their research needs, respectively. 


\subsection{Energy Use Issue and its Research Needs}

Energy efficiency of AM processes varies widely due to a variety of factors, including feedstocks, process types, load and use patterns, and geographic distributions. It has been suggested that AM enables distributed manufacturing which in turn makes the utilization of renewable energy sources easier [9]. To date there have been many energy studies on a variety of AM processes, especially laser sintering and FDM. However, most of the works have been done in laboratory instead of industrial settings. In addition, experimental protocols and measurement techniques vary from studies to studies, which makes comparison of results challenging. Usually, a large amount of energy is consumed to make AM feedstocks e.g. powder, resin, and filaments. Unfortunately, the embedded energy in these feedstocks is frequently estimated with large uncertainties. Moreover, few efforts have been put on optimizing energy efficiency but are largely limited to special processes and machines.

Some identified research needs are:

- Standardized methodology to characterize the energy consumption of AM processes;

- Improved estimate on embedded energy of various AM feedstocks;

- Energy impact of distributed AM practices; and

- Best practices for energy efficient printing and sharing of energy use outcomes with AM communities.

\subsection{Occupational Health Issue and its Research Needs}

Occupational health concerns have been raised about operating AM machines, especially with regard to particulate matters and VOCs. However, only limited work has been done to 
characterize and quantify these air emissions. In addition to the use of unusual feedstocks and novel processes, there is an increasing risk of common hazards being encountered in uncommon settings. AM has been making the production of small-run items accessible to new communities; as a result, places, people, and situations associated with AM technologies are diverging from typical profiles seen with conventional manufacturing processes. Sophisticated AM processes are, for instance, being used in startups and small prototyping shops, maker communities, basements and garages, and even classrooms where sophisticated ventilation and emission control systems may be lacking. In these cases, while many of the risks to health and safety may not be that dissimilar to those encountered in other manufacturing processes, the institutional knowledge and ability to identify and handle them is.

This emerging combination of conventional hazards in unconventional contexts, potential unconventional hazards, and increased exposure by the risk-naïve communities, is creating a unique set of challenges and uncertainties to ensuring the economic and societal benefits of AM through ensuring safe and responsible use. Understanding and addressing both the potential risks and benefits of AM to users across the board is critical to fully realize advantages of AM technologies.

The identified research needs are listed as follows:

- Understanding on the process mechanisms governing the formation of pollutants;

- Relationship between emission and feedstock materials/printing parameters/machine configurations; 
- Knowledge of the toxicology of emissions and exposure assessment and control, in particular, in classroom or home settings;

- Research and development on emission control and "safer-by-design" approaches for AM;

- Development of safer community practices;

- $\quad$ Risk assessment and management; and

- Innovation in education on occupational health and risks.

\subsection{Waste Issue and its Research Needs}

Thus far, little systematic information exists about the nature and quantity of wastes generated during $\mathrm{AM}$ processes and at the end of life of 3D printed parts. Quantitative information is needed regarding current and emerging practices related to AM. Without that information, it is difficult to investigate more specific questions. This information, which is not readily available, should include the type and quantity of materials used in AM, process conditions, and waste generation rates under different production settings and ends of life.

As such, research needs include:

- Characterization of production waste in both industrial and non-industrial settings;

- Standardization of the handling and recirculation of build materials such as the development of the international resin coding system for filaments [60, 61];

- End-of-life management of products in the distributed manufacturing setting;

- Development and communication of best practices for waste minimization with AM communities; 
- Study of drivers of/barriers to product lifetime extension enabled by AM; and

- Research regarding whether novel shapes/products/parts made possible by AM pose unique challenges for recycling, remanufacturing, or end-of-life waste management.

\subsection{Lifecycle Assessment Issue and its Research Needs}

Current LCA studies on AM processes or AM products reply on a variety of assumptions and simplifications. Often conflicting conclusions can be found in literature. Significant data gaps exist on upstream and downstream, that is, feedstock manufacturing and end-of-life management. In addition, much of data collected is from laboratory instead of actual application settings. All of these seriously limit the practical significance of the LCA studies on product/process improvements and policy making.

The identified research needs include:

- Standardized assessment of energy and material consumption for AM as well as conventional manufacturing;

- Methodologies to establish the supply-chain environmental footprint of different AM pathways, including data collection and sharing mechanisms;

- Scenarios for environmental impact of AM-enabled supply chain innovation;

- Impact of the wide adoption of AM machines;

- Collection and sharing of AM-related data for lifecycle assessment; and

- Change of end-of-life strategies after the wide diffusion of AM technologies. 


\subsection{Cross-cutting and Policy Issue and their Research Needs}

$\mathrm{AM}$, due to its distributed nature and direct connection with product design, has some unique features regarding environmental footprints. From a technology perspective, it requires crosscutting research efforts across the topic areas such as integrated product and process development [62] and standardized characterization [63] to fully realize AM's potential contributions to sustainability and minimize the environmental impacts and may require novel approaches. It also calls for better understanding of how AM-based production systems and value chains will affect overall resource consumption [4]. From a UK perspective, six research areas (design, supply chains, information flows, entrepreneurship, business models, and education) have been defined in order to develop understanding of how AM can enable more sustainable modes of production and consumption [5]. In addition, like any emerging technologies, AM raises a variety of potential policy issues, which span from operator exposure to hazards and risks, to product quality assurance, and public health. While some cross-cutting and policy questions may be answered using lifecycle, health, energy, and/or waste studies, others require supplementary research efforts.

Specifically, the following research needs are identified:

- Better integration of environmental sustainability into design for AM;

- Policy issues related to distributed manufacturing generally and interdisciplinary AM processes;

- Regulation on AM feedstock and material coding;

- Analysis of public perceptions of various uses of AM. 


\section{RECOMMENDATIONS}

The following sections propose some recommendations per the identified research needs.

\subsection{Energy Use Research}

Three main energy-related recommendations are listed as follows. Firstly, it is important to study energy-related opportunities and impacts presented by new build materials, including polymers, metals, biomaterials, ceramics, and composites/multi-materials as well as the energy embedded during raw material generation or any pre-determined material waste streams such as sacrificial support structures. Secondly, it is necessary to investigate the indirect energy impact of AM products, such as lightweight cars and energy systems such as batteries, as well as AM-enabled distributed manufacturing practices including distributed manufacturing centers integrated within the power grid. Thirdly, there is a need to standardize methodologies for the energy characterization of each AM process in order to compare AM processes with one another and with conventional manufacturing.

\subsection{Occupational Health Research}

Two main occupational health-related recommendations are listed as follows. Firstly, AM risk assessment and management is to be investigated systematically in two different aspects:

- The toxicity and hazardous nature of feedstock materials - in particular where fine powders such as metal powders are used; and

- Potential risks of gaseous and particulate emissions, especially where these may take the form of nanoparticles. For some cases, it is still not clear whether innocuous exposures 
could lead to long-term health impairment, in particular, to the young and vulnerable population.

Secondly, it is imperative to research "safer-by-design" approaches for AM applications. This calls for interdisciplinary collaborations to ensure that manufacturing guidelines draw on the latest understanding of risk management, governance, and use of design principles and approaches across the life stages and value chain of AM processes and products. Emphasis should be placed on implementing "safer-by-design" methodologies, standards, and cultures from an early stage within AM within different contexts - from large-scale users to startups to even maker communities.

\subsection{Waste Research}

The main waste-related recommendation is to identify and define unique challenges related to the waste from AM production processes and their end-of-life products. Such challenges are complicated by:

- Novel materials and multi-materials used during AM;

- Novel shapes and products and even product repairability made possible by AM;

- Medical applications, in particular, those enabled by 3D bioprinting; and

- Whether products are disposed in industrial or non-industrial settings.

In addition, end-of-life considerations must be adapted for the wide-scale adoption of AM processes. In particular, such considerations may cover the possible remanufacturing of products created via AM pathways including multi-material structures or hybrid composites, products 
customized on the basis of personal data such as patient-specific medical products, and waste streams resulting from decommissioned AM products, to name a few.

\subsection{Lifecycle Assessment Research}

Three main lifecycle assessment-related recommendations are listed as follows. Firstly, it is of importance to establish methodologies that are capable of capturing the supply chain footprint and describing scenarios of both conventional manufacturing and AM in order to compare the impact of alternative manufacturing pathways. The supply chain footprint covers the "cradle-togate" aspects of manufacturing. Analyses of this type aim to generate a detailed understanding of the environmental impact of translating energy and materials into finished products. The supply chains of AM-based manufacturing are marked by the digital integration (virtualization) and consolidation of manufacturing and assembly processes into individual AM process steps. In contrast, conventional mass-manufacturing supply chains are often characterized by a multitude of process steps, potentially performed at different locations around the globe. Some additional aspects should be noted too when building methodologies to capture the environmental impact of AM supply chains:

- Use of $\mathrm{AM}$ in practical manufacturing settings may require integration with complementary, potentially conventional, manufacturing techniques;

- Adoption of AM for routine manufacturing settings suggests a significant increase in manufacturing volume. Therefore, the methodologies designed to capture the environmental footprint of AM supply chains must be able to reflect the scalability (or lack thereof) of such digital fabrication processes; and

- Mass flows of raw materials should be incorporated into AM supply chain models. 
In addition, there is a need to develop systematic and standardized methodologies for the assessment of process material and energy consumption of AM and conventional processes. A consistent and reliable methodology to capture energy inputs should be integrated with a benchmarking effort based on the thermodynamic minimum of energy for raw material conversion [64]. The method developed by Cooperative Effort on Process Emissions in Manufacturing (CO2PE!) for conventional manufacturing processes $[65,66]$ may suit this purpose.

\subsection{Cross-cutting and Policy Issues}

While the cross-cutting and policy issues may be partially addressed by combining research from other categories, but that some additional research directions are also necessary. Five main crosscutting and policy-related recommendations are listed as follows. Firstly, there is a need to define cross-cutting and policy-related challenges due to the introduction of AM-enabled distributed manufacturing and other interdisciplinary AM processes such as bioprinting. In particular, under the distributed manufacturing model, manufacturing may be conducted at various distributed non-industrial setting locations, such as job shops, maker spaces, and even home garages, introducing policy and legal liability problems. Secondly, it is necessary to specify proper lifecycle assessments to different audiences in the policymaking community. Lifecycle assessments may be used differently when produced for internal or industry uses compared to assessments applied to distributed production systems. Thirdly, it is important to identify environmental impact-related research problems for prototyping and bespoke items, which may encompass lifecycle assessment, occupational health, energy use, and waste issues. Fourthly, it is critical to develop and disseminate an AM sustainability framework to ensure the sustainability 
of the production and energy/resource efficiency of 3D printers, use of renewable and biodegradable feedstocks, design of machines and feedstocks for safe use, development of takeback and recycling programs, and provision of easy-to-understand information on safe use and risk reduction. From this perspective, the traditional LCA framework may not be sufficient as widespread adoption of AM may trigger changes in many industrial sections for example polymer processing. To capture these market-mediated changes consequential LCA is needed $[67,68]$. In an even broader sense, life cycle sustainability assessment framework may be needed to consider the triple bottom line simultaneously [69]. Last but not least, intellectual property rights associated with AM-related remanufactured and spare parts must be defined. This includes both the availability of information that facilitates production of spare parts and repair (manuals and schematics) and whether aftermarket producers of spare parts and consumers/hobbyists may, or may not have the relevant rights to produce those parts.

\section{Summary and Discussion}

This summary paper aims to focus on the current state-of-the-art, research needs and related recommendations regarding to environmental implications of AM. As identified by the workshop participants, some notable identified are summarized:

- Lifecycle Assessment Issues: Research is needed into the supply chain footprint of additive manufacturing and the methodologies needed to compare entire pathways, from material extraction to finished product. There was also interest in a standardized assessment of process energy consumption for additive manufacturing. This research should utilize plausible scenarios of additive manufacturing methods looking towards the future. 
- Occupational Health Issues: There is a need for better risk assessment and management research related to additive manufacturing, including the toxicology of emissions, exposure control approaches, and exposure assessment. This work could include the development of "safer-by-design" principles, tools and approaches for additive processes.

- Energy Use Issues: Research is needed into new materials, quantifying the energy impacts of the products of additive manufacturing, and the development of standardized methodologies to compare energy use of additive compared with conventional manufacturing processes. This work might include consideration of additive manufacturing strategies applied to lightweight materials, batteries, insulation, or energy production technologies.

- Waste Issues: There is a need for research into management at the end of life of products produced using additive manufacturing, in addition to work on industrial production waste and whether novel shapes, products and parts made possible by additive manufacturing pose unique challenges for waste management.

- Cross-cutting and Policy Issues: A variety of policy research needs were identified, particularly further research into the regulatory implications of bioprinting. Other areas identified include the early identification of risks unique to additive manufacturing in "desktop" settings, liability for different types of users in different settings (schools, job shops, etc.), the use of lifecyle analysis by different constituent groups, and the public perception of various uses of additive manufacturing.

For illustration, four environmental implications-related scenarios have been listed as potential case studies [7]: Production of Metal Powder Bed Fusion Parts, Production of Polymer Powder 
Bed Fusion Parts, Community Center Maker Space, and Metal Part Repair using Directed Energy Deposition. They may form the basis for further discussion of the potential environmental impacts and associated research implications, raising key questions about the environmental and human health effects of various AM practices.

The research and development community has also been organizing notable efforts and events to address environmental implications of AM, in particular regarding the occupational health and safety science during various AM practices such as fused deposition modeling (FDM) and powder bed fusion. For example, Underwriters Laboratories (UL) organized the 2017 Safety Science of 3D Printing Summit in Atlanta in February 2017. Specifically, the summit shared the research progress on chemical and ultrafine particle emissions released during FDM printing and the participants agreed to move forward on developing an ANSI standard for measuring and assessing printer emissions for safe use in indoor spaces [70]. Furthermore, UL has been spearheading the effort in establishing the standard test method for particle and chemical emissions from 3D printers. As envisioned, the method will apply to freestanding printers typically found in schools, offices, libraries, homes and other non-industrial indoor spaces, providing measurement protocols for determining the emissions of particles (including ultrafine particles) and chemicals from diverse 3D printers, print media and print applications.

\section{Acknowledgements}

The work was partially supported by the National Science Foundation (NSF CMMI-1450529). This paper is based on the final report of the 2014 NSF workshop on "Environmental Implications of Additive Manufacturing” held on October 14-15, 2014, in Arlington, Virginia. 
Aaron Lovell of the Woodrow Wilson International Center for Scholars provided editorial assistance. The authors would like to thank all the workshop participants for their participation and inspiring discussion. In particular, we would like to thank the discussion leaders (Martin Baumers, Andrew Maynard, Joe Cresko, Reid Lifset, and Mark Greenwood) and the invited workshop speakers (David Rosen, David Bourell, Gideon Levy, Ming Leu, Robert Olson, Martin Baumers, Brent Stephens, and Tim Gutowski).

\section{References}

[1] Y. Huang, M.C. Leu. J. Mazumder, A. Donmez, Additive manufacturing: current state, future potential, gaps and needs, and recommendations, ASME J. of Manufacturing Sci. and Eng. 137 (2015) 014001-1-10.

[2] Wohlers Associates, Inc., Wohlers Report 2013: Additive Manufacturing and 3D Printing State of the Industry, Fort Collins, Colorado, 2013.

[3] R. Olson, 3-D printing: a boon or a bane? The Environmental Forum. 30(6) (2013) 34-38.

[4] S. Ford, M. Despeisse, Additive manufacturing and sustainability: an exploratory study of the advantages and challenges, Journal of Cleaner Production 137 (2016) 1573-1587.

[5] M. Despeisse, M. Baumers, P. Brown, F. Charnley, S. Ford, A. Garmulewicz, S. Knowles, T. Minshall, L. Mortara, F. Reed-Tsochas, Unlocking value for a circular economy through 3D printing: a research agenda, Technological Forecasting and Social Change 115 (2017) 75-84.

[6] J. Holmstrom, T. Gutowski, Additive manufacturing in operations and supply chain management: No sustainability benefit or virtuous knock-on opportunities? Journal of Industrial Ecology (2017). DOI: 10.1111/jiec.12580. 
[7] D. Rejeski, Y. Huang, Environmental and Health Impacts of Additive Manufacturing: An NSF Workshop Report. Woodrow Wilson Center, Washington DC. 2015.

[8] W. Morrow, H. Qi, I. Kim, J. Mazumder, S. Skerlos, Environmental aspects of laser-based and conventional tool and die manufacturing, Journal of Cleaner Production 15(10) (2007) 932-943.

[9] M. Kreiger, J.M. Pearce, Environmental life cycle analysis of distributed three-dimensional printing and conventional manufacturing of polymer products, ACS Sustainable Chemistry \& Engineering 1(12) (2013) 1511-1519.

[10] R. Huang, M. Riddle, D. Graziano, J. Warren, S. Das, S. Nimbalkar, J. Cresko, E. Masanet, Energy and emissions saving potential of additive manufacturing: the case of lightweight aircraft components, Journal of Cleaner Production 135 (2016) 1559-1570.

[11] P. Mognol, D. Lepicart, N. Perry, Rapid prototyping: energy and environment in the spotlight, Rapid prototyping journal 12(1) (2006) 26-34.

[12] R. Sreenivasan, A. Goel, D. Bourell, Sustainability issues in laser-based additive manufacturing, Physics Procedia 5 (2010) 81-90.

[13] M. Baumers, C. Tuck, D. Bourell, R. Sreenivasan, R. Hague, Sustainability of additive manufacturing: measuring the energy consumption of the laser sintering process, Proceedings of the Institution of Mechanical Engineers, Part B: Journal of Engineering Manufacture 225(12) (2011) 2228-2239.

[14] T. Reinhardt, G. Witt, Experimental analysis of the laser-sintering process from an energetic point of view, Laser 5 23(1) (2012) 5W.

[15] A. Verma, R. Rai, Energy efficient modeling and optimization of additive manufacturing processes, Solid Freeform Fabrication Symposium, Austin, TX (2013) 231-241. 
[16] V.A. Balogun, N.D. Kirkwood, P.T. Mativenga, Direct electrical energy demand in Fused Deposition Modelling, Procedia CIRP 15 (2014) 38-43.

[17] J. Ajay, A.S. Rathore, C. Song, C. Zhou, W. Xu, Don't Forget Your Electricity Bills!: An Empirical Study of Characterizing Energy Consumption of 3D Printers, Proceedings of the 7th ACM SIGOPS Asia-Pacific Workshop on Systems (2016) 7.

[18] X. Xu, S. Meteyer, N. Perry, Y.F. Zhao, Energy consumption model of binder-jetting additive manufacturing processes, International Journal of Production Research 53(23) (2015) 7005-7015.

[19] S. Meteyer, X. Xu, N. Perry, Y.F. Zhao, Energy and material flow analysis of binder-jetting additive manufacturing processes, Procedia CIRP 15 (2014) 19-25.

[20] N. Afshar-Mohajer, C.Y. Wu, T. Ladun, D. Rajon, Y. Huang, Characterization of particulate matters and total VOC emissions from a binder jetting 3D printer, Building and Environment. 93 (2015) 293-301.

[21] Y. Yang, L. Li, Y. Pan, Z. Sun, Energy Consumption Modeling of Stereolithography Based Additive Manufacturing Toward Environmental Sustainability, Journal of Industrial Ecology (2017). DOI: 10.1111/jiec.12589.

[22] M. Baumers, C. Tuck, R. Hague, I. Ashcroft, R. Wildman, A comparative study of metallic additive manufacturing power consumption, Solid freeform fabrication symposium (2010) 278-288.

[23] M. Baumers, C. Tuck, R. Wildman, I. Ashcroft, R. Hague, Shape complexity and process energy consumption in electron beam melting: A case of something for nothing in additive manufacturing?, Journal of Industrial Ecology (2016). DOI: 10.1111/jiec.12397. 
[24] M. Baumers, C. Tuck, R. Wildman, I. Ashcroft, R. Hague, Energy inputs to additive manufacturing: does capacity utilization matter? Solid freeform fabrication symposium (2011) $30-40$.

[25] B. Stephens, P. Azimi, Z. El Orch, T. Ramos, Ultrafine particle emissions from desktop 3D printers, Atmos. Environ. 79 (2013) 334-339.

[26] Y. Kim, C. Yoon, S. Ham, J. Park, S. Kim, O. Kwon, P.-J. Tsai, Emissions of nanoparticles and gaseous material from 3D printer operation, Environmental science \& technology 49(20) (2015) 12044-12053.

[27] L. Mendes, A. Kangas, K. Kukko, B. Mølgaard, A. Säämänen, T. Kanerva, I. Flores Ituarte, M. Huhtiniemi, H. Stockmann - Juvala, J. Partanen, Characterization of Emissions from a Desktop 3D Printer, Journal of Industrial Ecology (2017). DOI: 10.1111/jiec.12569.

[28] Q. Zhang, J.P. Wong, A.Y. Davis, M.S. Black, R.J. Weber, Characterization of Particle Emissions from Consumer Fused Deposition Modeling 3D Printers, Aerosol Science and Technology (just-accepted) (2017) 00-00.

[29] P. Steinle, Characterization of emissions from a desktop 3D printer and indoor air measurements in office settings, Journal of Occupational and Environmental Hygiene 13(2) (2016) 121-132.

[30] T.R. Simon, G.A. Aguilera, F. Zhao, Characterization of particle emission from fuse deposition modeling printers, ASME 2017 12th International Manufacturing Science and Engineering Conference collocated with the JSME/ASME 2017 6th International Conference on Materials and Processing, American Society of Mechanical Engineers (2017) V002T01A040. 
[31] O. Kwon, C. Yoon, S. Ham, J. Park, J. Lee, D. Yoo, Y. Kim, Characterization and Control of Nanoparticle Emission during 3D Printing, Environmental Science \& Technology 51 (2017) 10357-10368.

[32] P. Azimi, T. Fazli, B. Stephens, Predicting Concentrations of Ultrafine Particles and Volatile Organic Compounds Resulting from Desktop 3D Printer Operation and the Impact of Potential Control Strategies, Journal of Industrial Ecology (2017). DOI: 10.1111/jiec.12578.

[33] P. Graff, B. Ståhlbom, E. Nordenberg, A. Graichen, P. Johansson, H. Karlsson, Evaluating measuring techniques for occupational exposure during additive manufacturing of metals: A pilot study, Journal of Industrial Ecology 61 (2016) 582.

[34] R. Song, C. Telenko, Material and energy loss due to human and machine error in commercial FDM printers, Journal of Cleaner Production 148 (2017) 895-904.

[35] D. Pham, K. Dotchev, W. Yusoff, Deterioration of polyamide powder properties in the laser sintering process, Proceedings of the Institution of Mechanical Engineers, Part C: Journal of Mechanical Engineering Science 222(11) (2008) 2163-2176.

[36] K. Dotchev, W. Yusoff, Recycling of polyamide 12 based powders in the laser sintering process, Rapid Prototyping Journal 15(3) (2009) 192-203.

[37] H. Tang, M. Qian, N. Liu, X. Zhang, G. Yang, J. Wang, Effect of powder reuse times on additive manufacturing of Ti-6Al-4V by selective electron beam melting, Jom 67(3) (2015) 555-563.

[38] P. Mägi, A. Krumme, M. Pohlak, Recycling of PA-12 in Additive Manufacturing and the Improvement of its Mechanical Properties, Key Engineering Materials 674 (2016) 9-14.

[39] S. Kumar, A. Czekanski, Development of filaments using selective laser sintering waste powder, Journal of Cleaner Production 165 (2017) 1188-1196. 
[40] A. Díaz Lantada, A. de Blas Romero, Á. Sánchez Isasi, D. Garrido Bellido, Design and Performance Assessment of Innovative Eco - Efficient Support Structures for Additive Manufacturing by Photopolymerization, Journal of Industrial Ecology (2017). DOI: 10.1111/jiec. 12660 .

[41] X. Tian, T. Liu, Q. Wang, A. Dilmurat, D. Li, G. Ziegmann, Recycling and remanufacturing of 3D printed continuous carbon fiber reinforced PLA composites, Journal of Cleaner Production 142 (2017) 1609-1618.

[42] J. Pakkanen, D. Manfredi, P. Minetola, L. Iuliano, About the Use of Recycled or Biodegradable Filaments for Sustainability of 3D Printing, International Conference on Sustainable Design and Manufacturing (2017) 776-785.

[43] G.T. Pan, S. Chong, H.J. Tsai, W.H. Lu, T.C.K. Yang, The Effects of Iron, Silicon, Chromium, and Aluminum Additions on the Physical and Mechanical Properties of Recycled 3D Printing Filaments, Advances in Polymer Technology (2016). DOI: 10.1002/adv.21777.

[44] K.R. Haapala, F. Zhao, J. Camelio, J.W. Sutherland, S.J. Skerlos, D.A. Dornfeld, A review of engineering research in sustainable manufacturing, Journal of Manufacturing Science and Engineering 135(4) (2013) 041013.

[45] F. Le Bourhis, O. Kerbrat, J.Y. Hascoët, P. Mognol, Sustainable manufacturing: evaluation and modeling of environmental impacts in additive manufacturing, The International Journal of Advanced Manufacturing Technology 69(9-12) (2013) 1927-1939.

[46] J. Faludi, M. Baumers, I. Maskery, R. Hague, Environmental impacts of selective laser melting: do printer, powder, or power dominate?, Journal of Industrial Ecology (2016). DOI: 10.1111/jiec.12528. 
[47] S. Peng, T. Li, X. Wang, M. Dong, Z. Liu, J. Shi, H. Zhang, Toward a sustainable impeller production: Environmental impact comparison of different impeller manufacturing methods, Journal of Industrial Ecology (2017). DOI: 10.1111/jiec.12628.

[48] F. Walachowicz, I. Bernsdorf, U. Papenfuss, C. Zeller, A. Graichen, V. Navrotsky, N. Rajvanshi, C. Kiener, Comparative energy, resource and recycling lifecycle analysis of the industrial repair process of gas turbine burners using conventional machining and additive manufacturing, Journal of Industrial Ecology (2017). DOI: 10.1111/jiec.12637.

[49] K. Kellens, R. Mertens, D. Paraskevas, W. Dewulf, J.R. Duflou, Environmental Impact of Additive Manufacturing Processes: Does AM contribute to a more sustainable way of part manufacturing?, Procedia CIRP 61 (2017) 582-587.

[50] K. da Silva Barros, P. Zwolinski, Influence of the use/user profile in the LCA of 3D printed products, Procedia CIRP 50 (2016) 318-323.

[51] J. Faludi, C. Bayley, S. Bhogal, M. Iribarne, Comparing environmental impacts of additive manufacturing vs traditional machining via life-cycle assessment, Rapid Prototyping Journal 21(1) (2015) 14-33.

[52] F. Cerdas, M. Juraschek, S. Thiede, C. Herrmann, Life cycle assessment of 3D printed products in a distributed manufacturing system, Journal of Industrial Ecology (2017). DOI: 10.1111/jiec.12618.

[53] C. Baechler, M. DeVuono, J.M. Pearce, Distributed recycling of waste polymer into RepRap feedstock, Rapid Prototyping Journal 19(2) (2013) 118-125.

[54] M. Gebler, A.J.S. Uiterkamp, C. Visser, A global sustainability perspective on 3D printing technologies, Energy Policy 74 (2014) 158-167. 
[55] J. Bours, B. Adzima, S. Gladwin, J. Cabral, S. Mau, Addressing Hazardous Implications of Additive Manufacturing: Complementing Life Cycle Assessment with a Framework for Evaluating Direct Human Health and Environmental Impacts, Journal of Industrial Ecology (2017). DOI: 10.1111/jiec.12587.

[56] F. Le Bourhis, O. Kerbrat, L. Dembinski, J.-Y. Hascoet, P. Mognol, Predictive model for environmental assessment in additive manufacturing process, Procedia CiRP 15 (2014) 26-31.

[57] Z. Liu, Q. Jiang, Y. Zhang, T. Li, H.-C. Zhang, Sustainability of 3D Printing: A Critical Review and Recommendations, ASME 2016 11th International Manufacturing Science and Engineering Conference, American Society of Mechanical Engineers 2 (2016) pp. V002T05A004.

[58] J. Kietzmann, L. Pitt, P. Berthon, Disruptions, decisions, and destinations: Enter the age of 3-D printing and additive manufacturing, Business Horizons 58(2) (2015) 209-215.

[59] B.R. Ringeisen, R.K. Pirlo, P.K. Wu, T. Boland, Y. Huang, W. Sun, Q. Hamid, D.B. Chrisey, Cell and organ printing turns 15: diverse research to commercial transitions, MRS Bulletin, 38 (2013) 834-843.

[60] E.J. Hunt, C. Zhang, N. Anzalone, J.M. Pearce, Polymer recycling codes for distributed manufacturing with 3-D printers, Resources, Conservation and Recycling 97 (2015) 24-30.

[61] S. Chong, H.L. Chiu, Y.C. Liao, S.T. Hung, G.T. Pan, Cradle to Cradle® design for 3D printing, Chemical Engineering 45 (2015) 1669-1674.

[62] L. Hao, D. Raymond, G. Strano, S. Dadbakhsh, Enhancing the sustainability of additive manufacturing, IET Conference Publications (2010) 390.

[63] M. Mani, K.W. Lyons, S.K. Gupta, Sustainability Characterization for Additive Manufacturing, Journal of Research (NIST JRES)-119.016 (2014) 419-428. 
[64] T. Gutowski, S. Jiang, D. Cooper, G. Corman, M. Hausman, J.A. Manson, T. Schudeleit, K. Wegener, M. Sabelle, J. Ramos-Grez, D.P. Sekulic. Note on the rate and energy efficiency limits for additive manufacturing, Journal of Industrial Ecology (2017) DOI: 10.1111/jiec.12664.

[65] K. Kellens, W. Dewulf, M. Overcash, M.Z. Hauschild, J.R. Duflou, Methodology for systematic analysis and improvement of manufacturing unit process life-cycle inventory (UPLCI) - CO2PE! initiative (cooperative effort on process emissions in manufacturing). Part 1: Methodology description, The International Journal of Life Cycle Assessment 17(1) (2012) 69-78.

[66] K. Kellens, W. Dewulf, M. Overcash, M.Z. Hauschild, J.R. Duflou, Methodology for systematic analysis and improvement of manufacturing unit process life-cycle inventory (UPLCI) - CO2PE! initiative (cooperative effort on process emissions in manufacturing). Part 2: Case studies, The International Journal of Life Cycle Assessment 17(2) (2012) 242-251.

[67] J.M. Earles, A. Halog, Consequential life cycle assessment: a review, The International Journal of Life Cycle Assessment 16(5) (2011) 445-453.

[68] J.M. Earles, A. Halog, P. Ince, K. Skog, Integrated economic equilibrium and life cycle assessment modeling for policy - based consequential LCA, Journal of Industrial Ecology 17(3) (2013) 375-384.

[69] J.B. Guinee, R. Heijungs, G. Huppes, A. Zamagni, P. Masoni, R. Buonamici, T. Ekvall, T. Rydberg, Life cycle assessment: past, present, and future, Environmental Science and Technology 45 (2011) 90-96. 
[70] Your Health \& 3D Printers: UL Presents New Research During 3D Printing Summit. http://industries.ul.com/blog/your-health-3d-printers-ul-presents-new-research-during-3dprinting-summit, 2017 (accessed 09.10.17). 